\title{
The Importance of Knowing the Basic First Aid Measures During Social Isolation of the Elderly
}

Eva Dolenc ( $\nabla$ eva.dolenc@zf.uni-lj.si )

University of Ljubljana: Univerza v Ljubljani https://orcid.org/0000-0002-8740-1186

Damjan Slabe

University of Ljubljana: Univerza v Ljubljani

Ivan Eržen

National Institute of Public Health Slovenia

Uroš Kovačič

University of Ljubljana: Univerza v Ljubljani

Research article

Keywords: first aid, social isolation, elderly

Posted Date: August 26th, 2021

DOI: https://doi.org/10.21203/rs.3.rs-840698/v1

License: (c) (i) This work is licensed under a Creative Commons Attribution 4.0 International License.

Read Full License 


\section{Abstract}

Background: The vulnerability of the elderly population increases with natural and other disasters. Consequent social isolation affects their health. Health problems, which can lead to emergencies, can be an even greater burden during times of social isolation. Early identification and action in terms of first aid for the most common emergencies that threaten an individual's health or life affect these conditions. We aimed to examine the knowledge of first aid in the most common emergencies that threaten elderly people's health and life among a Slovenian population, focusing on the elderly people's knowledge.

Methods: A cross-sectional population-based survey was conducted on 1079 respondents. Data were collected with a structured questionnaire. Statistically significant differences in average ratings among different age groups were determined with one-way ANOVA followed by a post hoc test. Significant differences between the categories of age groups were determined using the $\chi^{2}$ square test followed by appropriate post hoc testing for multiple comparisons. By regression analysis (Spearman's rho and Pearson Correlation), we determined the correlations.

Results: Our survey results indicated that Slovenes are aware of the importance of first aid knowledge and feel personally responsible for acquiring and developing this knowledge. The most surprising finding of our research is the high level of knowledge of recognising some of the most common conditions that occur in old age and taking action in response to them. Simultaneously, most of the knowledge tested does not depend on the person's age or the time since that person was last educated in first aid. Nevertheless, out of all age groups, those older than 80 stand out. The respondents' general opinion is that the elderly over 80 years of age need less first aid knowledge. Furthermore, their first aid knowledge is also somewhat worse, especially when recognising sudden illness.

Conclusions: Older than 80 are the most vulnerable psycho physically and socially, especially in natural and other disasters such as a pandemic. In the same time, their disaster preparedness from a first aid perspective is poor. There is a need to raise awareness and provide guidance on emergency preparedness to older people.

\section{Background}

As the global population ages [1], the percentage of old patients accessing medical care also increases [2]. They face various health problems, which can lead to emergencies such as stroke, hypoglycaemia in people with diabetes, hip injuries due to falls, out-of-hospital cardiac arrest (OHCA), and similar [1, 3]. Due to the increased risk, elderly people are a vulnerable group of the population $[4,1]$. Their vulnerability increases with natural and other disasters, leading to higher mortality of the elderly population $[5,6,7]$. After disasters, the elderly face more problems than other age groups [8]. They are more likely to face a variety of health and mobility problems, such as inadequate financial resources, lack of personal transport, and insufficient social networks $[9,10]$. After earthquakes, the occurrence of post-traumatic stress disorder is higher among the elderly than among other age groups [8]. In both the societal and the 
scientific dialogues surrounding the COVID pandemic, however, older people have been treated as vulnerable, helpless, and in need of society's protection [11]. They are the main target group of most of the policies due to their high risk of presenting complications from COVID-19 [12]. One of the primary protective measures during the pandemic is physical distance. The physical distancing regulations instituted to control COVID-19 have had significant psychosocial consequences [13]. While robust social restrictions (quarantine and social distancing) are necessary to prevent the spread of COVID-19, it is critical to bear in mind that social distancing should not be the same as social disconnection $[14,15]$. During the COVID pandemic, social disconnection causes loneliness and social isolation [14], defined as an objective lack of interactions with others or the wider community [15]. However, social isolation among older adults is also a 'serious public health concern' because of their heightened risk of cardiovascular, immune, neurocognitive, and mental health problems [16]. Notably, there is a large body of literature documenting the negative health effects of social isolation $[17,18]$. Forced isolation, loneliness, and fear of contracting the disease are tough challenges, especially for frail, elderly people [19, 20, 21, 22]. In contrast, people with adequate social relationships have a greater likelihood of survival compared to those with poor or insufficient social relationships [23]. It has recently been documented that social distancing during COVID-19 pandemic also negatively affects mental and physical health in older people [24]. Health problems, which can lead to emergencies, are greatest burden for the elderly during times of social isolation. Before the pandemic, most cardiac arrest victims were in their late sixties, $85 \%$ of them collapse at home, and half are witnessed by a family member or friend who usually is over the age of 55 [25]. Notably, higher numbers of OHCA in 2020, coupled with a reduction in short-term outcomes, were correlated to the COVID-19 pandemic [26, 27, 28, 29, 30]. The lockdown, as well as the spread of COVID19 among healthcare workers, led to a reduction, and in some cases to the suppression, of home care services (day-care, home care assistance, Alzheimer services) usually provided to frail older people [21]. This situation presents unique problems to healthcare providers and systems [2]. Therefore, in the current situation, promoting self-help and positive coping and reducing isolation appear imperative. Active outreach seems a necessity, especially for older adults [31].

In times of social isolation, the elderly are even more dependent on self-help or mutual help between relatives. Early identification and action in terms of first aid (FA), in the most common emergencies that threaten an individual's health or life, affects the outcome of these conditions [32]. In order to increase general awareness about emergency medical FA measures, public education is required. The knowledge of FA can be a great help to elderly people in the case of injury or acute disease. However, the effective educational planning relies on an accurate assessment of the baseline knowledge of the population [33]. Therefore, we aimed to examine the knowledge of FA in the most common emergencies that threaten an elderly's health or life among the Slovenian population, focusing on elderly people's knowledge. The conclusions could guide the future framework of policy orientations on how to improve FA knowledge and confidence for giving FA among elderly people.

\section{Methods}




\section{Study design}

A cross-sectional population-based survey was conducted in 2019. Data collection was performed by The Public Opinion and Mass Communication Research Centre of the Faculty of Social Sciences of the University of Ljubljana. The survey population was adult persons who are residents of the Republic of Slovenia. The size of this population in Slovenia is $1.700,000$. A representative, randomly selected sample among people older than 18 years was prepared by the Statistical Office of the Republic of Slovenia. The selection of units (persons) included in the sample is carried out on the basis of the Central Register of Population of Slovenia as a sample list. The selection is a random two-stage, where ultimately each person in the population is equally likely to be included in the sample. Participants were invited to participate in the study. Final results of the success of survey: the response rate was $59 \%$, the participation rate was $64 \%$ and the rejection rate was $28 \%$. There were 139 inaccessible units in the whole sample (displaced, deceased, inappropriate addresses, etc.) excluded from final analysis, which represents $7 \%$ of the total sample. The representations and statistical analysis of the data are based on a system of sampling weights that reduce the bias in the results due to the method of sampling and conducting the survey. All subjects were interviewed face-to-face by trained interviewers, and they completed a structured, pre-tested questionnaire. The interviewers interrupted the interviewees only to clarify a question if required, but they did not reveal any information about the questions.

\section{Questionnaire}

Data were collected with a structured questionnaire (see the appendix A). A literature review of previous studies was done to identify potential items for the questionnaire. It was designed on pre-existing empirical research studies by the authors of the present paper, dealing with various aspects of first aid. The questionnaire was pre-tested and evaluated by expert evaluators. The questionnaire consisted of demographic data and three sections: 1) attributing the importance of FA knowledge and responsibility for FA to certain groups of the population, 2) recognising the most common emergencies occurring in old age, 3) FA measures in the event of the most common emergencies occurring in old age.

\section{Statistical analysis}

The gathered data were analysed using SPSS ver. 24 software package (SPSS Inc., Chicago, IL, USA). The demographic data were interpreted using descriptive statistics. The average ratings of assessing the importance of FA knowledge for certain groups and the importance of responsibility for raising FA knowledge for certain groups were assessed using a Linkert scale (from 1-lowest grade to 5 - highest grade) and expressed as means \pm SD (standard deviation). Statistically significant differences in average ratings among different age groups were determined with one-way ANOVA followed by a post hoc Tukey test with appropriate adjustment of the $p$-value for multiple comparisons. Dependent variables obtained by substantive questions were expressed as percentages (\%) of affirmative/correct answers, and then the statistically significant differences between the different categories of age groups (independent variable) 
were determined using the $\chi^{2}$ square test followed by appropriate post hoc testing for multiple comparisons. Due to multiple comparisons, the level of statistical significance was adjusted $(p<0.05)$. By regression analysis (Spearman's rho and Pearson Correlation), we determined the correlation between the variables FA knowledge (achieved number of points on the knowledge test) and the time that has elapsed since the last FA training (on ranked values) and the age (in years) of the respondents.

\section{Results}

The demographic data of 1079 participants are presented in Table 1. The respondents were older than 18, mostly (37\%) from the age group over 60 years. Just under a third of all the respondents have a secondary or higher education. Just over half of those over the age of $60(198 / 402)$ are under the age of $70 ; 15 \%$ of all the respondents are older than 80 . Of those over $60,29 \%$ have primary education or less, $26 \%$ vocational education, $22 \%$ secondary and $23 \%$ high, higher or university education. More than half of all the respondents were in FA training for the last time more than ten years ago; $72 \%$ of those over the age of 60 were in such training more than 10 years ago, and $11 \%$ of the elderly have never had such training.

Table 1

Demographic data of all respondents $(n=1079)$

\begin{tabular}{|c|c|c|c|c|c|}
\hline \multirow[t]{2}{*}{ sex } & M & \multicolumn{4}{|l|}{$\mathrm{F}$} \\
\hline & $49 \%$ & $51 \%$ & & & \\
\hline \multirow[t]{2}{*}{ age (years), all } & $\begin{array}{l}\text { less than } \\
30\end{array}$ & $\begin{array}{l}\text { from } 31 \\
\text { to } 45\end{array}$ & $\begin{array}{l}\text { from } 46 \text { to } \\
60\end{array}$ & $\begin{array}{l}61 \text { and } \\
\text { more }\end{array}$ & \\
\hline & $16 \%$ & $23 \%$ & $24 \%$ & $37 \%$ & \\
\hline \multirow[t]{2}{*}{$\begin{array}{l}\text { age (years), older than } 60 \text { years }(n= \\
402)\end{array}$} & 61 to 69 & 70 to 79 & $\begin{array}{l}80 \text { and } \\
\text { more }\end{array}$ & & \\
\hline & $51 \%$ & $34 \%$ & $15 \%$ & & \\
\hline \multirow[t]{2}{*}{ education, all } & $\begin{array}{l}\text { primary } \\
\text { school }\end{array}$ & $\begin{array}{l}\text { high } \\
\text { school }\end{array}$ & gymnasium & $\begin{array}{l}\text { college, } \\
\text { university }\end{array}$ & \\
\hline & $17 \%$ & $22 \%$ & $31 \%$ & $31 \%$ & \\
\hline \multirow[t]{2}{*}{ number of years from last FA course, all } & $\begin{array}{l}1 \text { and } \\
\text { less }\end{array}$ & $\begin{array}{l}\text { from } 1 \\
\text { to } 5\end{array}$ & $\begin{array}{l}\text { from } 6 \text { to } \\
10\end{array}$ & $\begin{array}{l}\text { more } \\
\text { than } 10\end{array}$ & never \\
\hline & $13 \%$ & $18 \%$ & $9 \%$ & $55 \%$ & $5 \%$ \\
\hline \multirow[t]{2}{*}{$\begin{array}{l}\text { number of years from last FA course, } \\
\text { older than } 60 \text { years }(n=402)\end{array}$} & $\begin{array}{l}1 \text { and } \\
\text { less }\end{array}$ & $\begin{array}{l}\text { from } 1 \\
\text { to } 5\end{array}$ & $\begin{array}{l}\text { from } 6 \text { to } \\
10\end{array}$ & $\begin{array}{l}\text { more } \\
\text { than } 10\end{array}$ & never \\
\hline & $5 \%$ & $8 \%$ & $3 \%$ & $73 \%$ & $10 \%$ \\
\hline
\end{tabular}


A comparison of the assessment of the importance of FA knowledge for individual age categories in the population is shown in Table 2. The average assessment of the importance of FA knowledge for all groups is 4.49 (standard deviation $=0.607$ ) on a scale from 1 to 5 , where 1 means not important at all and 5 means very important. Therefore, the respondents from all age groups believe that FA knowledge is important or very important for all age groups of the population. All the respondents attributed the highest importance of FA knowledge to students and employed people (mean $=4.77$; standard deviation $=0.509$ ) and younger retirees (mean $=4.64$; standard deviation $=0.652$ ), which is statistically significantly more than attribution to the importance of skills for older retirees and children and adolescents. People above 46 believed this type of knowledge is more important among children and adolescents than among people younger than 30. Other differences in the assessment of the importance of FA knowledge for different population groups between different age groups were not statistically significant.

Table 2

The importance of FA knowledge for certain age groups of population

\begin{tabular}{|c|c|c|c|c|c|c|}
\hline \multirow[t]{3}{*}{ POPULATION } & \multicolumn{6}{|c|}{ AGE GROUPS OF RESPONDENTS } \\
\hline & $\begin{array}{l}\text { all }(n= \\
1079)\end{array}$ & $\begin{array}{l}<30 \text { years } \\
(n=169)\end{array}$ & $\begin{array}{l}31-45 \text { years } \\
(n=246)\end{array}$ & $\begin{array}{l}46-60 \text { years } \\
(n=262)\end{array}$ & $\begin{array}{l}>60 \text { years } \\
(n=402)\end{array}$ & $\begin{array}{l}{ }^{\# p} \\
\text { value }\end{array}$ \\
\hline & $\overline{\mathbf{x}}$ & $\overline{\mathbf{x}}$ & $\overline{\mathbf{x}}$ & $\overline{\mathbf{x}}$ & $\overline{\mathbf{x}}$ & \\
\hline $\begin{array}{l}\text { Children and } \\
\text { adolescents }\end{array}$ & $\begin{array}{l}4,29( \pm \\
0,249)^{a}\end{array}$ & $\begin{array}{l}4,11( \pm \\
0,954)\end{array}$ & $4,24( \pm 0,966)$ & $\begin{array}{l}4,37( \pm \\
0,874)^{\star}\end{array}$ & $\begin{array}{l}4,34( \pm \\
0,942)^{\star}\end{array}$ & ,020 \\
\hline $\begin{array}{l}\text { Students and } \\
\text { staff }\end{array}$ & $\begin{array}{l}4,77( \pm \\
0,509)^{b}\end{array}$ & $\begin{array}{l}4,84( \pm \\
0,441)\end{array}$ & $4,77( \pm 0,502)$ & $4,73( \pm 0,553)$ & $\begin{array}{l}4,77( \pm \\
0,509)\end{array}$ & ,177 \\
\hline $\begin{array}{l}\text { Younger } \\
\text { retirees }\end{array}$ & $\begin{array}{l}4,64( \pm \\
0,652)^{c}\end{array}$ & $\begin{array}{l}4,64( \pm \\
0,582)\end{array}$ & $4,59( \pm 0,643)$ & $4,62( \pm 0,636)$ & $\begin{array}{l}4,67( \pm \\
0,652)\end{array}$ &, 531 \\
\hline Older retirees & $\begin{array}{l}4,27( \pm \\
0,924)^{\mathrm{a}}\end{array}$ & $\begin{array}{l}4,19( \pm \\
0,879)\end{array}$ & $4,28( \pm 3,938)$ & $4,33( \pm 0,858)$ & $\begin{array}{l}4,26( \pm \\
0,924)\end{array}$ & ,469 \\
\hline
\end{tabular}

\# - p value comparing different age groups of respondents (ANOVA); * statistically significantly different from the group up to 30 years after performing post hoc comparison

Letters a, b, c represents statistically significant differences in the attributed importance of FA knowledge of the selected population: there is a statistically significant difference between groups with a different letter in the assessment of the importance of FA knowledge for certain groups

The respondents believe that all subjects are important or very important (rated on a scale of 1 to 5 , where 1 means not important at all and 5 means very important) for contributing to FA knowledge (mean $=4.2$; standard deviation $=0.066$ ). The respondents attribute the highest responsibility for raising FA to different organizations or individuals, and there are no statistically significant differences between them $(p>0.05)$. They attribute a statistically significantly lower level of responsibility for raising FA knowledge to the media or a personal physician than to organizations and individuals. Different age groups of 
respondents are unanimous in this opinion, as there are no significant differences between them $(p>0.05$; except in the case of a personal physician, for which the ANOVA test is used to determine the sig. due to significant global effect, which is not proven by post hoc tests). (Table 3 )

Table 3

Assessment of the attributed responsibility of the selected stakeholders involved in the dissemination of first aid knowledge

\begin{tabular}{|c|c|c|c|c|c|c|}
\hline \multirow[t]{3}{*}{ STAKEHOLDERS } & \multicolumn{6}{|c|}{ AGE GROUPS OF RESPONDENTS } \\
\hline & $\begin{array}{l}\text { all }(n= \\
1079)\end{array}$ & $\begin{array}{l}<30 \text { years } \\
(n=169)\end{array}$ & $\begin{array}{l}31-45 \text { years } \\
(n=246)\end{array}$ & $\begin{array}{l}46-60 \text { years } \\
(n=262)\end{array}$ & $\begin{array}{l}>60 \text { years } \\
(n=402)\end{array}$ & $\begin{array}{l}\# p \\
\text { value }\end{array}$ \\
\hline & $\overline{\mathbf{x}}$ & $\overline{\mathbf{x}}$ & $\overline{\mathbf{x}}$ & $\overline{\mathbf{x}}$ & $\overline{\mathbf{x}}$ & \\
\hline \multirow[t]{2}{*}{ Personal doctor } & 4,08 & 3,97 & 3,98 & 4,05 & 4,20 & 0,042 \\
\hline & $\begin{array}{l}( \pm \\
1,140) \\
a\end{array}$ & $( \pm 1,003)$ & $( \pm 1,210)$ & $( \pm 1,152)$ & $( \pm 1,135)$ & \\
\hline \multirow[t]{2}{*}{ Mass media } & 3,90 & 3,88 & 3,87 & 3,95 & 3,90 & 0,797 \\
\hline & $\begin{array}{l}( \pm \\
0,992) \\
\text { b }\end{array}$ & $( \pm 0,981)$ & $( \pm 1,047)$ & $( \pm 0,964)$ & $( \pm 0,983)$ & \\
\hline \multirow{2}{*}{$\begin{array}{l}\text { Different } \\
\text { organizations }\end{array}$} & 4,35 & 4,43 & 4,37 & 4,31 & 4,34 & 0,571 \\
\hline & $\begin{array}{l}( \pm \\
0,885) \\
c\end{array}$ & $(0,769)$ & $( \pm 0,855)$ & $( \pm 0,848)$ & $( \pm 0,969)$ & \\
\hline \multirow[t]{2}{*}{ Individual } & 4,33 & 4,42 & 4,33 & 4,29 & 4,33 & 0,583 \\
\hline & $\begin{array}{l}( \pm \\
0,934) \\
c\end{array}$ & $( \pm 0,842)$ & $( \pm 0,882)$ & $( \pm 0,889)$ & $( \pm 1,026)$ & \\
\hline \multicolumn{7}{|c|}{$\begin{array}{l}\text { \# - p value comparing different age groups of respondents (ANOVA); * there was no significant } \\
\text { differences after post hoc test was performed }\end{array}$} \\
\hline \multicolumn{7}{|c|}{$\begin{array}{l}\text { Letters a, b, c represents statistically significant differences in the attributed responsibility of the } \\
\text { selected stakeholders: there is a statistically significant difference in attributing the meaning of } \\
\text { responsibility between groups (stakeholders) that have a different letter }(p<0.05 \text {; significance for } \\
\text { letters } \mathrm{c} \text { is } \mathrm{p}=0,588 \text { ) }\end{array}$} \\
\hline
\end{tabular}

The correlation between the variables FA knowledge (combined from the number of points achieved on the knowledge test; maximal total score is 14) and the time elapsed since the last FA training (in time categories), are statistically significantly different from zero. The latter implies that there is a correlation between variables. However, this relationship is negligible $(-0.083)$. The variables number of points scored on the knowledge test and age of the respondents (in years) are not correlated. (Table 4) 
Table 4

Results of regression analysis; testing the correlation between the variables FA knowledge with time since last FA training (time categories) or age (years) of respondents

\begin{tabular}{|c|c|c|c|c|}
\hline & & & $\begin{array}{l}\text { FA knowledge } \\
\text { test score }\end{array}$ & $\begin{array}{l}\text { Time since last } \\
\text { FA training }\end{array}$ \\
\hline \multirow[t]{5}{*}{$\begin{array}{l}\text { Spearman's } \\
\text { rho }\end{array}$} & \multirow[t]{2}{*}{ FA Knowledge score } & $\begin{array}{l}\text { Correlation } \\
\text { Coefficient }\end{array}$ & 1,000 &,$- 083^{*}$ \\
\hline & & Sig. (2-tailed) & . & ,006 \\
\hline & \multirow[t]{3}{*}{$\begin{array}{l}\text { Time since last FA training } \\
\text { (categories) }\end{array}$} & $\begin{array}{l}\text { Correlation } \\
\text { Coefficient }\end{array}$ &,$- 083^{*}$ & 1,000 \\
\hline & & Sig. (2-tailed) & ,006 & . \\
\hline & & & $\begin{array}{l}\text { FA knowledge } \\
\text { test score }\end{array}$ & Age (years) \\
\hline \multirow[t]{4}{*}{$\begin{array}{l}\text { Pearson } \\
\text { Correlation }\end{array}$} & \multirow[t]{2}{*}{ FA Knowledge score } & $\begin{array}{l}\text { Pearson } \\
\text { Correlation }\end{array}$ & 1 & ,043 \\
\hline & & Sig. (2-tailed) & & 163 \\
\hline & \multirow[t]{2}{*}{ Age (years) } & $\begin{array}{l}\text { Pearson } \\
\text { Correlation }\end{array}$ & ,043 & 1 \\
\hline & & Sig. (2-tailed) & , 163 & \\
\hline
\end{tabular}

About $90 \%$ of all the respondents knew the signs and symptoms of a stroke or heart attack. The proportion of them was lower in the case of worsening diabetes (hypoglycaemia). About two-thirds of all respondents would recognise it (Table 5). In the oldest ( $>60$ years) age group, the proportion of the respondents who knew the signs and symptoms of hypoglycaemia was almost $26 \%$ lower than in the age group of $46-60$ years, which was statistically significantly different $\left(\chi^{2}=31.196 ; p<0.001\right)$ and the share of correct answers in the oldest age group was also statistically significantly lower compared to other age groups younger than 46 years $(p<0.001)$. There are no significant differences between the groups in the case of the proportion of correct responses regarding heart attack or stroke recognition. There are also no significant differences between age groups in the knowledge of the correct measures in the case of heart attack and stroke; here, too, the share of correct answers is $89 \%$ (heart attack) and $98 \%$ (stroke). In contrast to the recognition of hypoglycaemia, those over 60 years of age know the FA measures in the case of hypoglycaemia statistically significantly better than respondents under 46 years of age. In the group over the age of $6065 \%$ more people can take correct FA action in the event of hypoglycaemia than in the group under the age of $30\left(x^{2}=45.625 ; p<0.001\right)$. The proportion of correct answers is by far the lowest $(16 \%)$ in relation to basic resuscitation procedures, as most respondents would prefer to use an AED instead of chest compressions. 
Table 5

Recognition of health conditions (emergencies) and knowledge of correct FA emergency measures in respondents from different age groups

\begin{tabular}{|c|c|c|c|c|c|}
\hline \multirow{3}{*}{$\begin{array}{l}\text { HEALTH } \\
\text { CONDITIONS }\end{array}$} & \multicolumn{5}{|c|}{ AGE GROUPS OF RESPONDENTS } \\
\hline & $\begin{array}{l}<30 \text { years }(\mathrm{n} \\
=169)\end{array}$ & $\begin{array}{l}31-45 \text { years }(\mathrm{n} \\
=246)\end{array}$ & $\begin{array}{l}46-60 \text { years }(n \\
=262)\end{array}$ & $\begin{array}{l}>60 \text { years }(n \\
=402)\end{array}$ & $\begin{array}{l}\text { all }(n= \\
1079)\end{array}$ \\
\hline & \multicolumn{5}{|c|}{ correct RECOGNITION of health condition } \\
\hline Hypoglycaemia & $72 \% a$ & $68 \%{ }^{a}$ & $74 \%^{a}$ & $55 \%$ b & $65 \%$ \\
\hline Stroke & $91 \%{ }^{a}$ & $89 \%{ }^{a}$ & $90 \%^{a}$ & $87 \%^{a}$ & $89 \%$ \\
\hline Heart attack & $94 \%$ a,b & $94 \% a, b$ & $95 \% \mathrm{~b}$ & $89 \%{ }^{a}$ & $93 \%$ \\
\hline $\begin{array}{l}\text { HEALTH } \\
\text { CONDITIONS }\end{array}$ & \multicolumn{5}{|c|}{ correct FA MEASURES } \\
\hline Hypoglycaemia & $43 \%{ }^{\mathrm{a}}$ & $60 \% \mathrm{~b}$ & $68 \%$ b,c & $71 \% \mathrm{c}$ & $63 \%$ \\
\hline Stroke & $98 \%^{a}$ & $98 \%^{a}$ & $99 \%^{a}$ & $97 \%^{a}$ & $99 \%$ \\
\hline Heart attack & $90 \%{ }^{a}$ & $90 \%{ }^{a}$ & $87 \%^{a}$ & $90 \%^{a}$ & $89 \%$ \\
\hline CPR & $19 \%{ }^{a}$ & $18 \%{ }^{a}$ & $17 \%^{a}$ & $13 \%^{a}$ & $16 \%$ \\
\hline
\end{tabular}

If we take a closer look at the knowledge of people over 60 , we find that a statistically significant difference in the proportion of correct answers occurs in recognition of hypoglycaemia: $45 \%$ of people aged 61 to 69 have more knowledge than people over 80 , which is statistically significant $\left(\chi^{2}=7.018 ; p=\right.$ 0.030). The same is true for recognising a heart attack (Table 6). Approximately $70 \%$ of all people over 60 know the correct measures in case of hypoglycaemia; the proportions of correct answers in identifying other conditions and correct FA measures range between 87 and $97 \%$, and there are no statistically significant differences between different groups of the elderly $(p>0.05)$. Most respondents would prefer to use an AED over chest compressions when performing basic resuscitation procedures. The proportion of those older than 80 is lower than in younger age groups, but statistically insignificant $\left(\chi^{2}=2.561 ; p=\right.$ $0.278)$. 
Table 6

Recognition of emergency medical conditions and knowledge of emergency measures of FA among respondents over 60 years of age

\begin{tabular}{|c|c|c|c|c|}
\hline \multirow{3}{*}{$\begin{array}{l}\text { HEALTH } \\
\text { CONDITIONS }\end{array}$} & \multicolumn{4}{|c|}{ AGE GROUPS OF RESPONDENTS } \\
\hline & $\begin{array}{l}61-69 \text { let }(49,3 \%, n \\
=198)\end{array}$ & $\begin{array}{l}70-79 \text { let }(34,8 \%, n \\
=140)\end{array}$ & $\begin{array}{l}>80 \text { let }(15,9 \%, n \\
=64)\end{array}$ & $\begin{array}{l}\text { all }(n= \\
402)\end{array}$ \\
\hline & \multicolumn{4}{|c|}{ correct RECOGNITION of health condition } \\
\hline Hypoglycaemia & $61 \%{ }^{a}$ & $53 \% a, b$ & $42 \%{ }^{b}$ & $55 \%$ \\
\hline Stroke & $86 \%^{a}$ & $91 \%{ }^{\mathrm{a}}$ & $80 \%{ }^{a}$ & $87 \%$ \\
\hline Heart attack & $91 \%{ }^{a}$ & $94 \%{ }^{a}$ & $73 \%$ b & $89 \%$ \\
\hline $\begin{array}{l}\text { HEALTH } \\
\text { CONDITIONS }\end{array}$ & \multicolumn{4}{|l|}{ correct FA MEASURES } \\
\hline Hypoglycaemia & $76 \%{ }^{a}$ & $70 \%$ a & $61 \%$ & $71 \%$ \\
\hline Stroke & $98 \%{ }^{a}$ & $96 \%{ }^{a}$ & $98 \%{ }^{a}$ & $97 \%$ \\
\hline Heart attack & $88 \%{ }^{a}$ & $89 \%{ }^{a}$ & $97 \%{ }^{a}$ & $90 \%$ \\
\hline CPR & $11 \%{ }^{a}$ & $14 \%{ }^{\mathrm{a}}$ & $19 \%$ a & $13 \%$ \\
\hline
\end{tabular}

\section{Discussion}

The results of our survey indicate that Slovenes are aware of the importance of FA knowledge. They believe that it is essential for different age groups (children, young people, students, employees, as well as for younger and older retirees). The result is encouraging, as it has previously been shown that it is the amateur who, by giving FA, has a significant impact on improving health and survival in the case of OHCA [32]. At the same time, it is important that our respondents, in addition to attributing responsibility to organizations such as the Red Cross, also feel to be personally responsible for raising knowledge about FA measures and do not transfer this responsibility to the media and physicians. Slabe [33] finds that in present-day Slovenian society, giving FA is seen as a high moral duty of an individual and also a responsibility for acquiring knowledge. The most surprising finding of our research is the high level of knowledge of recognising some of the most common conditions that occur in old age and taking action in response to them. Between 88 and $98 \%$ of all the respondents recognise the signs and symptoms of a stroke or heart attack and know the correct measures of FA in the event of their occurrence. The exceptions where the proportion of correct responses was lower in all the respondents were recognising and responding to hypoglycaemia and understanding correct CPR. At the same time, most of the skills 
tested do not even depend on the person's age or the time since that person was most recently educated in FA. Out of all age groups, those older than 80 stand out. Notably, the general opinion of all the respondents is that the elderly over 80 years of age need less FA knowledge (Table 2). In addition, we determined that they also know somewhat less (Table 6), especially when recognising sudden illness (hypoglycemia and heart attack). Nevertheless, they are the most vulnerable, fragile psychophysically/medically, as well as socially, especially in emergencies such as a pandemic $[19,21]$. Notably, loneliness in older adults is most prevalent in the 'oldest old', referring to individuals aged 80 and over [23].

People over the age of 60 are less able to recognise hypoglycaemia signs and symptoms. On the other hand, their knowledge of correct FA measures in the case of this condition is significantly better compared to younger people, which is an interesting finding. In a related study, Turk et al. [36] determined the knowledge of diabetic people in Slovenia regarding their disease. The mean score obtained is 8.0 ( \pm 2.4) out of a possible 14. They conclude that elderly people show a relatively low level of general knowledge of their disease. In addition, our results show that people over the age of 60 are also less able to recognise the signs and symptoms of a heart attack when compared to younger people are. If we examine the knowledge of people over the age of 60 in more detail, we find that in both emergencies (recognising hypoglycaemia and heart attacks), it is worse in people over 80 . In times of social isolation during the COVID pandemic, this can lead to negative health outcomes. Existing studies suggest that patients with OHCA in 2020 were older with a high burden of hypertension, diabetes, and had physical limitations [37]. Poor outcomes with COVID-19 infection correlate with vascular risk factors such as hypertension, coronary artery disease, and diabetes mellitus [38]. The elderly COVID-19 population had a significantly higher burden of diabetes than the younger cohort did [39]. Belani et al. [40] also demonstrated that COVID-19 infection is significantly associated with acute ischemic stroke. In addition, there was a significant drop in frequency emergency service use in March 2020 [41] and the proportion of patients who had an OHCA and were admitted alive decreased in the pandemic period $[27,29]$. Changes associated with reduced surviving of OHCA were longer emergency medical services arrival times, higher proportions of OHCAs occurring at home (and/or unwitnessed) and lower provision of CPR by citizenrescuers (laypeople). During the COVID-19 period, Baert et al. [42] observed a decrease in CPR initiation regardless of whether patients were suspected of SARS-CoV-2 infection or not. Accordingly, the proportion of patients dead on arrival of the EMS was larger [27].

Because the knowledge of CPR in times of social isolation is even more important, it should be emphasized that the share of correct answers among the participants in our study in the case of CPR did not exceed 19\%. Most respondents in our study, both young and old, believe that in order to help an unconscious person who is not breathing, it is more important to use an AED than to start chest compression, which is not correct [43]. Similarly, Richman et al. [44], in their observational study, found a misunderstanding of the use of AEDs in CPR among people in a senior living community. Findings of poorer CPR knowledge among the elderly are also confirmed by others $[45,46]$. In addition to knowledge, there is also a strongly de creasing level of willingness to use an AED as age increased [46]. Vaillancourt et al. [47] identified the facilitators and barriers among the elderly to CPR training and CPR performance. 
For both behaviors under study, attitudinal beliefs such as believing that CPR could help a victim and that it should be initiated before EMS arrival played a significant role. On the other hand, although the elderly are aware of the importance of FA knowledge, their (too) low self-confidence about this knowledge is often a problem. The elderly have lower confidence in their ability to apply resuscitation than younger people [45]. A similar result was reported by Dobbie et al. [48]; they found that the older the person is, the less likely he/she is confident to administer CPR with or without instructions from an emergency call handler. The reason may be that they are less likely to be CPR trained or show a willingness to be CPR trained. Caap and colleagues [49] also link the low level of CPR knowledge to the fact that the majority (57\%) of the respondents have not yet attended a CPR course. In the present study, we found that the last time the majority of our respondents were in FA training was more than 10 years ago. Given that their knowledge does not depend on the time since the last training, the question arises as to where they have acquired this knowledge.

\section{Limitations}

The reasons and sources of acquiring FA knowledge in other medical situations could also be explored in more detail. One of the limitations of our research is that we only found theoretical knowledge of FA. Behavior in a real situation could be different. In a real situation of cardiac arrest, Park et al. [50] found that people over 60 perform CPR at a lower quality. Takei and colleagues [51] confirmed that older eyewitnesses are less likely to perform CPR in reality. In addition, our research's limitation is also that the questionnaire was focused to be made on a representative sample of all the population of Slovenia, but not on a representative sample of the elderly, although the total number of respondents older than 60 was not small $(n=402)$.

\section{Conclusions}

Because the elderly, as a vulnerable group, are subject to injuries and sudden illnesses, as well as the risks posed by COVID-19 infection, they are even more dependent on self-help and mutual assistance from partners in the event of an accident. With the poor access of the emergency medical service, the importance of FA knowledge of the elderly during the social isolation due to COVID-19 epidemic increases even more. It is encouraging that we found solid knowledge regarding some emergencies in our research. The low level of knowledge regarding understanding CPR with AEDs and recognising hypoglycaemia poses a challenge and commitment to engaging key stakeholders in FA training from all amateur people. Important emphasis should be placed on those over 80 , who are most exposed and vulnerable in social isolation.

\section{Abbreviations}

FA: first aid

OHCA: out-of-hospital cardiac arrest 
CPR: cardiopulmonary resusciation

AED: Automated external defibrillator

SD: standard deviation

\section{Declarations}

\section{Ethics approval and consent to participate}

The research was approved by the Republic of Slovenia National Medical Ethics Committee, Ministry of Health (Number: 0120-73/2019/6). Prior to the interviewer's visit, respondents received a letter about the purpose of the questionnaire, the possibility of refusal to participate during survey, anonymity and their protection with General Data Protection Regulation. When the interviewer visited them, they verbally agreed to participate.

\section{Consent to publish}

Not applicable.

\section{Availability of data and materials}

The datasets generated during and analysed during the current study are available in the ADP - Social science data archives repository, https://www.adp.fdv.uni-lj.si/opisi/.

\section{Competing interests}

The authors declare that they have no competing interests.

\section{Funding}

The research was funded by the authors.

\section{Authors contributions}

ED gets all credit to drafting of the manuscript (quantitative analysis of data and conception of manuscript). ED and UK conducted a design and interpretation of data. DS and IE reviewed the article and literature. UK supervised the writing and critically revised the final version to be published. The manuscript has been read and approved by all the authors, each author believes that the manuscript represents honest work. All authors agree with the potential publication of the article.

\section{Acknowledgements}

Not applicable. 


\section{References}

1. World Health Organization. (2015) World report on ageing and health. Geneva: WHO Press, World Health Organization. Accessed December 8, 2020. http://www.who.int/ageing/publications/worldreport-2015/en/.

2. Smith BJ, Lim MH. How the COVID-19 pandemic is focusing attention on loneliness and social isolation. Public Health Res Pract. 2020;30(2):3022008. doi:10.17061/phrp3022008

3. First Aid Education European Network. First Aid Training for Older People Trainer Guide. Paris, The Global First Aid Reference Centre, 2013.

4. OECD/EU. Health at a Glance: Europe 2018: State of Health in the EU Cycle, OECD Publishing, Paris/EU, Brussels, 2018. Accessed December 10, 2020. https://doi.org/10.1787/health_glance_eur2018-en

5. Astill S, Miller E. "We expect seniors to be able to prepare and recover from a cyclone as well as younger members of this community": Emergency Management's Expectations of Older Adults Residing in Aging, Remote Hamlets on Australia's Cyclone-Prone Coastline. Disaster Med Public Health Prep. 2018;12(1):14-18. doi: 10.1017/dmp.2017.33

6. Knowlton K, Rotkin-Ellman M. Preparing for Climate Change: Lessons for Coastal Cities From Hurricane Sandy, 2014. Accessed December 22, 2020. https://www. nrdc.org/sites/default/files/hurricane-sandycoastal-floodingreport.pdf

7. McClelland E, Amlôt R, Rogers MB, Rubin GJ, Tesh J, Pearce JM. Psychological and Physical Impacts of Extreme Events on Older Adults: Implications for Communications. Disaster Med Public Health Prep. 2017;11(1):127-134. doi: 10.1017/dmp.2016.118

8. Liang Y, Zeng H, Liu Yu, Xu A, Liu W. Prevalence of post-traumatic stress disorder after earthquakes among the elderly in China: A metaanalysis. World J Emerg Med. 2021;12 (2):137-142. doi: 10.5847/wjem.j.1920-8642.2021.02.009

9. Li H, Wang L, Shi Z, Zhang Y, Wu K, Liu P. Diagnostic utility of the PTSD Checklist in detecting ptsd in Chinese earthquake victims. Psychol Rep. 2010;107(3):733-9. doi: 10.2466/03.15.20.PR0.107.6.733739.

10. Sezgin U, Punamäki RL. Earthquake trauma and causal explanation associating with PTSD and other psychiatric disorders among South East Anatolian women. J Affect Disord. 2012;141(2-3):43240. doi: 10.1016/j.jad.2012.03.005.

11. Klusmann V, Kornadt AE. Current directions in views on ageing. Eur J Ageing.2020;26:1-4. doi: 10.1007/s10433-020-00585-4

12. Mesa Vieira C, Franco OH, Gómez Restrepo C, Abel T. COVID-19: The forgotten priorities of the pandemic. Maturitas 2020;136:38-41. doi: 10.1016/j.maturitas.2020.04.004

13. Smith AB. Vulnerable Populations: The Elderly. In: Martin, Heron, Moreno-Walton, Jones (ed) Diversity and Inclusion in Quality Patient Care. 2016;161-168. doi:10.1007/978-3-319-22840-2_15 
14. Hwang TJ, Rabheru K, Peisah C, Reichman W, Ikeda M. Loneliness and social isolation during the COVID-19 pandemic. Int Psychogeriatr. 2020;32(10):1217-1220. doi:10.1017/S1041610220000988

15. Leigh-Hunt N, Bagguley D, Bash K, et al. An overview of systematic reviews on the public health consequences of social isolation and loneliness. Public health. 2017;152,157-171. https://doi.org/10.1016/j.puhe.2017.07.035

16. Gerst-Emerson K, Jayawardhana J. Loneliness as a public health issue: the impact of loneliness on health care utilisation among older adults. Am J Public Health. 2015;105(5):1013-9. doi: 10.2105/AJPH.2014.302427

17. Holt-Lunstad J, Smith TB, Layton JB. Social relationships and mortality risk: a meta-analytic review. PLoS Med. 2010;7(7):e1000316

18. Nicholson NR. A review of social isolation: an important but underassessed condition in older adults. J Prim Prev . 2012;33(2-3):137-52. doi: 10.1007/s10935-012-0271-2

19. Armitage R, Nellums LB. COVID-19 and the consequences of isolating the elderly. Lancet Public Health. 2020;5(5):e256. doi: 10.1016/S2468-2667(20)30061-X

20. McCrae N, Correa A, Chan T, Jones S, de Lusignan S. Long-term conditions and medicallyunexplained symptoms: feasibility of cognitive behavioural interventions within the improving access to Psychological Therapies Programme. J Ment Health. 2015;24(6):379-84. doi: 10.3109/09638237.2015.1022254

21. Bianchetti A, Bellelli G, Guerini F, et al. Improving the care of older patients during the COVID-19 pandemic. Aging Clin Exp Res. 2020;32(9):1883-1888. doi: 10.1007/s40520-020-01641-w

22. Panossian A, Cave MW, Patel BA, Brooks EL, Flint MS, Yeoman MS. Effects of age and social isolation on murine hippocampal biochemistry and behavior. Mech Ageing Dev. 2020;191:111337. doi: 10.1016/j.mad.2020.111337

23. Poscia A, Stojanovic J, La Milia DI, et al. Interventions targeting loneliness and social isolation among the older people: An update systematic review. Exp Gerontol. 2018;102:133-144. doi: 10.1016/j.exger.2017.11.017

24. Sepúlveda-Loyola W, Rodríguez-Sánchez I, Pérez-Rodríguez P, et al. Impact of Social Isolation Due to COVID-19 on Health in Older People: Mental and Physical Effects and Recommendations. J Nutr Health Aging. 2020; 25:1-10. doi: 10.1007/s12603-020-1469-2

25. Vaillancourt C, Stiell IG, Canadian Cardiovascular Outcomes Research Team (CCORT). Cardiac arrest care and emergency medical services in Canada. Can J Cardiol. 2004; 20:1081-90

26. Singh S, Fong HK, Mercedes BR, Serwat A, Malik FA, Desai R. COVID-19 and out-of-hospital cardiac arrest: A systematic review and meta-analysis. Resuscitation. 2020;156:164-166. doi: 10.1016/j.resuscitation.2020.08.133

27. Baldi E, Sechi GM, Mare $C$ et al. COVID-19 kills at home: the close relationship between the epidemic and the increase of out-of-hospital cardiac arrests. Eur Heart J. 2020;41(32):3045-3054. doi: 10.1093/eurheartj/ehaa508 
28. Odone A, Delmonte D, Scognamiglio T, Signorelli C. COVID-19 deaths in Lombardy, Italy: data in context. Lancet Public Health. 2020;5(6):e310. doi: 10.1016/S2468-2667(20)30099-2

29. Marijon E, Karam N, Jost D, et al. Out-of-hospital cardiac arrest during the COVID-19 pandemic in Paris, France: a population-based, observational study. Lancet Public Health. 2020;5(8):e437-e443. doi: 10.1016/S2468-2667(20)30117-1

30. Scquizzato T, Landoni G, Paoli A, et al. Effects of COVID-19 pandemic on out-of-hospital cardiac arrests: A systematic review. Resuscitation. 2020;29:S0300-9572(20)30527-X. doi:

10.1016/j.resuscitation.2020.10.020

31. De Leo D, Dello Buono M, Dwyer J. Suicide among the elderly: the long-term impact of a telephone support and assessment intervention in northern Italy. Br J Psychiatry. 2002; 181:226-9. doi:

10.1192/bjp.181.3.226

32. Hasselqvist-Ax I, Riva G, Herlitz J, et al. Early cardiopulmonary resuscitation in out-of-hospital cardiac arrest. N Engl J Med. 2015;372(24):2307-15. doi: 10.1056/NEJMoa1405796

33. Sadeghi-Hokmabadi E, Vahdati SS, Rikhtegar R, Ghasempour K, Rezabakhsh A. Public knowledge of people visiting Imam Reza hospital regarding stroke symptoms and risk factos. BMC Emerg Med. 2019;19(1):36. doi: 10.1186/s12873-019-0250-5

34. Slabe D. Prva pomoč kot oblika solidarnosti v sodobni slovenski družbi. Dissertation, University of Ljubljana, 2013.

35. Poscia A, Stojanovic J, La Milia DI, et al. Interventions targeting loneliness and social isolation among the older people: An update systematic review. Exp Gerontol. 2018;102:133-144. doi: 10.1016/j.exger.2017.11.017

36. Turk E, Palfy M, Prevolnik Rupel V, Isola A. General knowledge about diabetes in the elderly diabetic population in Slovenia. ZdravVestn. 2012;81(7-

8). https://vestnik.szd.si/index.php/ZdravVest/article/view/592 Accessed 11 Dec 2020

37. Lai PH, Lancet EA, Weiden MD, et al. Characteristics Associated With Out-of-Hospital Cardiac Arrests and Resuscitations During the Novel Coronavirus Disease 2019 Pandemic in New York City. JAMA Cardiol. 2020;5(10):1154-63. doi: 10.1001/jamacardio.2020.2488

38. Zhou F, Yu T, Du R, et al. Clinical course and risk factors for mortality of adult inpatients with COVID19 in Wuhan, China: a retrospective cohort study. Lancet. 2020;395(10229):1054-1062. doi: 10.1016/S0140-6736(20)30566-3

39. Desai R, Singh S, Parekh T, Sachdeva S, Sachdeva R, Kumar G. COVID-19 and diabetes mellitus: A need for prudence in elderly patients from a pooled analysis. Diabetes Metab Syndr. 2020;14(4):683685. doi: 10.1016/j.dsx.2020.05.021

40. Belani P, Schefflein J, Kihira S, et al. COVID-19 Is an Independent Risk Factor for Acute Ischemic Stroke. AJNR Am J Neuroradiol. 2020;41(8):1361-1364. doi: 10.3174/ajnr.A6650

41. Santana R, Sousa JS, Soares P, et al. The Demand for Hospital Emergency Services: Trends during the First Month of COVID-19 Response. Port J Public Health. 2020;38:30-36. doi:

$10.1159 / 000507764$ 
42. Baert $\mathrm{V}$, Jaeger $\mathrm{D}$, Hubert $\mathrm{H}$, et al. Assessment of changes in cardiopulmonary resuscitation practices and outcomes on 1005 victims of out-of-hospital cardiac arrest during the COVID-19 outbreak: registry-based study. Scand J Trauma Resusc Emerg Med. 2020;18;28(1):119. doi: 10.1186/s13049020-00813-x.

43. European Resusciation Centre. First aid in European Resuscitation Council Guidelines for Resuscitation, 2015. Accessed December 10, 2020. https://cprguidelines.eu/.

44. Richman PB, Bobrow BJ, Clark L, Noelck N, Sanders AB. Ability of citizens in a senior living community to perform lifesaving cardiac skills and appropriately utilise AEDs. J Emerg Med. 2007;33(4):395-9. doi: 10.1016/j.jemermed.2007.02.020

45. Brinkrolf P, Bohn A, Lukas RP, et al. Senior citizens as rescuers: Is reduced knowledge the reason for omitted lay-resuscitation-attempts? Results from a representative survey with 2004 interviews. PLoS One. 2017;12(6):e0178938. doi: 10.1371/journal.pone.0178938

46. Krammel M, Schnaubelt S, Weidenauer $D$, et al. Gender and age-specific aspects of awareness and knowledge in basic life support. PLoS One. 2018;13(6):e0198918. doi:

10.1371/journal.pone.0198918

47. Vaillancourt C, Kasaboski A, Charette M, et al. Barriers and facilitators to CPR training and performing CPR in an older population most likely to witness cardiac arrest: a national survey. Resuscitation. 2013;84(12):1747-52. doi: 10.1016/j.resuscitation.2013.08.001

48. Dobbie F, MacKintosh AM, Clegg G, Stirzaker R, Bauld L. Attitudes towards bystander cardiopulmonary resuscitation: Results from a cross-sectional general population survey. PLoS One. 2018;13(3):e0193391. doi: 10.1371/journal.pone.0193391

49. Caap P, Nebsbjerg AM, Rasmussen S, et al. Elderly Lack Fundamental Knowledge of CPR and Mobile Phone Use With Importance for Effective Dispatcher Assisted CPR Performance. Circulation 2016;134:A15990. Accessed December 22, 2020. https://www.ahajournals.org/doi/10.1161/circ.134.suppl_1.15990

50. Park HJ, Jeong WJ, Moon HJ, et al. Factors Associated with High-Quality Cardiopulmonary Resuscitation Performed by Bystander. Emerg Med Int. 2020;8356201. doi: 10.1155/2020/8356201

51. Takei $Y$, Nishi T, Matsubara H, Hashimoto M, Inaba H. Factors associated with quality of bystander CPR: the presence of multiple rescuers and bystander-initiated CPR without instruction.

Resuscitation. 2014;85(4):492-8. doi: 10.1016/j.resuscitation.2013.12.019

\section{Supplementary Files}

This is a list of supplementary files associated with this preprint. Click to download.

- AppendixA5.docx

- STROBEchecklistv4combinedPlosMedicineED1.docx 